\title{
Expedição escolas do Brasil: primeiras aproximações de uma pesquisa
}

\author{
Brazilian schools expedition: first approaches to a research
}

Sofia Lerche Vieira

Doutora

Universidade Estadual do Ceará - UECE

Fortaleza, Ceará - Brasil.

sofialerche@gmail.com

Iasmin da Costa Marinho

Mestre

Universidade Estadual do Rio Grande do Norte - UERN Mossoró, Rio Grande do Norte - Brasil.

iasmincosta@uern.br

Eloisa Maia Vidal

Doutora

Universidade Estadual do Ceará - UECE

Fortaleza, Ceará - Brasil.

eloisamvidal@yahoo.com.br

\begin{abstract}
Resumo: Este artigo apresenta os primeiros achados de uma pesquisa sobre a implementação de políticas educacionais em 23 escolas públicas localizadas nos seis biomas brasileiros. A pesquisa trabalha com três temas geradores - política educacional, cidadania global e diversidade territorial -, procurando identificar a presença deles na escola, e adota, como vertente teórica, a perspectiva analítica inspirada em Dale, Ball e Torres. Como procedimento metodológico, foi utilizado o modelo misto de pesquisa e o estudo de casos múltiplos. As primeiras aproximações ao tema mostram que cada escola é fruto de uma história que lhe confere uma identidade e define como as políticas e as iniciativas são acolhidas ou secundarizadas. A relação da escola com a cidadania global pareceu frágil e pouco efetiva na maioria dos estabelecimentos. Percebeu-se, ainda, que significativo número de escolas apresenta baixo compromisso com as questões ambientais e a sustentabilidade do território do entorno.
\end{abstract}

Palavras chave: política educacional; cidadania global; diversidade territorial; escolas públicas; governança.

Abstract: This paper presents the the first findings of a research on the implementation of educational policies in 23 public schools located in the six Brazilian biomes. The research works with three founder topics - educational policy, global citizenship and territorial diversity - seeking to identify their presence at school and adopts as a theoretical approach the analytical perspective inspired by Dale, Ball and Torres. As a methodological procedure, mixed research model and the study of multiple cases were used. The first approaches to the thopic show that each school is the result of a story that gives it an identity and defines how policies and initiatives are accepted or left behind. The school's relationship with global citizenship seemed fragile and ineffective in most establishments. It was also noticed that a significant number of schools have a low commitment to environmental issues and the sustainability of the surrounding territory.

Key-words: educational policy; global citizenship; territorial diversity; public schools; governance.

Cite como

\section{(ABNT NBR 6023:2018)}

VIEIRA, Sofia Lerche; MARINHO, Iasmin Costa; VIDAL, Eloisa Maia. Expedição Escolas do Brasil: primeiras aproximações de uma pesquisa. Dialogia, São Paulo, n. 40, p. 1-20, e20576, jan./mar. 2022. Disponível em: https://doi.org/10.5585/40.2022.20576.

\section{American Psychological Association (APA)}

Vieira, S. L., Marinho, I. C., \& Vidal, E. M. (2022, jan./mar.) Expedição Escolas do Brasil: primeiras aproximações de uma pesquisa. Dialogia, São Paulo, 40, p. 1-20, e20576. https://doi.org/10.5585/40.2022.20576. 
Introdução

\begin{abstract}
A inserção do Brasil no sistema global ocorreu com a própria conquista e colonização do território. E deixou-nos três heranças: a vastidão do espaço geográfico, a forte assimetria regional e as escandalosas desigualdades sociais (BACELAR, 2008, s. p.).
\end{abstract}

Conhecer escolas e algumas de suas diferentes expressões no território nacional foi o objetivo de um projeto de pesquisa, desenvolvido com apoio financeiro do Conselho Nacional de Desenvolvimento Científico e Tecnológico (CNPq) entre 2017 e 2021. Agregando grupos de pesquisa de diferentes universidades brasileiras, o estudo investigou temas relativos à implementação de políticas educacionais em 23 escolas públicas localizadas nos seis biomas brasileiros: Mata Atlântica, Cerrado, Pampa, Pantanal, Amazônia e Caatinga.

Tendo como referência três temas geradores (TORRES, 2014) - política educacional, cidadania global e diversidade territorial - buscou-se identificar a presença e/ou ausência deles na escola. Pretendeu-se compreender as políticas em sua dimensão de ação de governo (SOUZA, 2006) e suas manifestações no espaço escolar (VIDAL; VIEIRA, 2014; MOREIRA; AIRES, 2015; WERLE; KOETZ; MARTINS, 2015; WERLE; AUDINO, 2015).

Este artigo representa uma primeira aproximação aos achados da pesquisa realizada nas escolas. Está organizado em quatro seções: a primeira apresenta os fundamentos teóricos; a segunda aborda os temas centrais do estudo; a terceira detalha a metodologia adotada e quarta apresenta as percepções mais presentes no conjunto das escolas, seguidas de considerações finais.

\title{
1 Fundamentos teóricos da pesquisa
}

Dentre as vertentes teóricas contemporâneas de política educacional, optou-se por perspectivas com potencial de oferecer lentes interpretativas para um melhor aprofundamento do objeto. Considerando os temas a analisar, recorreu-se a fundamentos buscados em diversos autores do campo em questão.

\subsection{Governança Educacional Multiescalar}

Uma das escolhas teóricas recaiu sobre teoria da governança educacional multiescalar (DALE, 2010), que analisa as configurações da política educacional em um contexto de mudanças na estrutura do Estado, em que novos atores entram em cena. Nesse sentido, ao lado dos entes estatais associados à oferta de serviços educacionais, como governos e agentes públicos, estão presentes outras instituições de coordenação, como o mercado, a comunidade e o lar (família). 
Também devem ser incluídas nas atividades de governança o financiamento, a propriedade, o fornecimento e a regulação.

Finalmente, além dos estados nacionais, é preciso considerar também outros agentes como organismos internacionais. Nessa configuração, estão presentes pelo menos três níveis: o supranacional, o nacional e o subnacional. Os elementos da governança (escalas de governança, instituições de coordenação e atividades de governança) se cruzam em um desenho lógico passível de análise.

Interessa aprofundar o movimento das instâncias de formulação e de implementação de políticas, mais especificamente, as três escalas/níveis, referidos. No caso brasileiro, as escalas podem ou não estar presentes no contexto da realidade observada. No caso das iniciativas do Governo Federal focalizadas no estudo, a avaliação de larga escala refere-se a um contexto mais amplo, em que a escala supranacional é estratégica na formulação de políticas. Tal critério não se aplica às demais iniciativas focalizadas pela pesquisa, como os programas de distribuição de material didático, alimentação e transporte escolar, em que interagem a escala nacional e as escalas subnacionais. Trata-se, pois, de perspectiva fecunda à análise dos temas geradores do estudo.

\subsection{As escolas farem as politicas}

Ao lado da teoria da governança educacional multiescalar, buscou-se, em Ball, Maguire e Braun (2016, p. 9), fundamentos da ideia de que também "as escolas fazem as políticas". Tal esforço parte do pressuposto de que é necessário "conceituar, de forma diferente, a relação entre a política (policy) e a prática". Embora as políticas sejam formuladas para todas as escolas, estas diferem muito entre si, pois

\footnotetext{
algumas escolas têm mais recursos; as escolas têm diferentes consumos de estudantes e têm necessidades diferentes; as escolas são mais ou menos populares em suas comunidades locais: as escolas têm diferentes capacidades para recrutar e reter professores. Todos esses fatores, entre outros, tornam as escolas locais únicos de atuação de políticas (p. 9).
}

Sob tal perspectiva, as escolas não apenas implementam políticas, como contribuem para seu redimensionamento e sua reinterpretação. Embora os formuladores de políticas não sejam responsáveis pela sua implementação, na prática a equipe escolar - gestores, professores, funcionários e até mesmo alunos (a depender de sua atuação) - pode reinventar as políticas. Se os atores que as formulam não são os mesmos que as implementam, na prática, os implementadores de políticas podem aproximar-se ou distanciar-se dos objetivos previstos na formulação de iniciativas. 
Ball, Maguire e Braun (2016, p. 13) argumentam que a política "é feita pelos e para os professores: eles são atores e sujeitos, sujeitos e objetos das políticas”. Observe-se, nesse sentido, que “a política não é 'feita' em um ponto no tempo; em nossas escolas é sempre um processo de 'tornar-se', mudando de fora para dentro e de dentro para fora. É analisada e revista, bem como, por vezes, dispensada ou simplesmente esquecida” (BALL, MAGUIRE E BRAUN, 2016, p. 15).

Compreender como as políticas educacionais chegam às escolas implica em observar um duplo movimento. Em primeiro lugar, precisa-se compreender como as iniciativas transitam entre as escalas de governança, no caso do estudo em foco, em particular as ações advindas do Governo Federal com o objetivo de prover recursos às escolas para o desempenho de suas atividades cotidianas. Em segundo lugar, é necessário lembrar que, uma vez adentrando o território escolar, as políticas sofrem influências diversas dos atores que circulam em seu interior. Aqui é necessário trazer à luz a dimensão da "cultura organizacional escolar", como se verá no subtópico a seguir.

\subsection{Cultura Organizacional Escolar}

Como organizações complexas, as escolas são instituições sujeitas a influências diversas, onde são dimensões analíticas importantes para sua compreensão: "as relações entre a 'estrutura' (formal) e 'ação' (informal) e entre o 'exterior' (fora) e o 'interior' (dentro) da escola" (TORRES, 2005, p. 435). A autora considera a existência de

\footnotetext{
complexas relações de implicação mútua entre a estrutura e a acção organizacional. O entendimento destas interconexões passará pela perspectivação da acção humana quer como dependente das estruturas que a constrangem, quer como produtoras de novas lógicas e de novos sentidos que contribuem para a sua alteração, redefinição e modificação. E neste sentido, o comportamento humano passa a ser concebido como revestido de margens relativas de autonomia, relativamente às quais pode desenvolver criativamente diversas (p. 438).
}

A articulação entre o "exterior" e o "interior" da escola, por sua vez, é outro componente importante de sua cultura organizacional no sentido de que existe uma articulação mútua entre os fatores externos e internos à escola e cada unidade escolar reage às influências externas com base em suas configurações internas. Isso porque, ao chegarem às escolas, as políticas se defrontam com suas especificidades, relacionadas às diferentes expressões da autonomia escolar.

A cultura escolar é construção simbólica resultante de variáveis distintas. Embora possam ser semelhantes às condições de organização das escolas, cada unidade lida com os fatores externos e com a estrutura, a partir de particularidades próprias. Por isso mesmo, a cultura de cada escola interfere na forma como as políticas são processadas em seu interior. 
A contribuição da cultura organizacional da escola ao objeto de análise permite compreender que, se "as escolas fazem as políticas", não a fazem como querem, mas a partir de uma trajetória singular na construção de sua história. Compreende-se, assim, como, embora sejam as mesmas e concebidas com objetivos comuns, as políticas são sujeitas a mudanças quando se materializam no chão da escola. Com relação a esse aspecto, o território é um elemento chave para a compreensão das relações construídas na cultura organizacional da escola.

Considerando os temas geradores apresentados na primeira seção e os fundamentos teóricos que orientam a pesquisa, discutidos na segunda seção, serão apresentadas algumas percepções sobre o que foi encontrado nas escolas visitadas. Como primeira aproximação, procurase dar destaque aos aspectos comuns, pontuando, no entanto, algumas especificidades associadas a algumas escolas dos biomas.

\section{Temas geradores como recurso de análise}

Conforme referido, três temas geradores - política educacional, cidadania global e diversidade territorial -, mutuamente articulados, orientaram a concepção e o desenvolvimento da pesquisa.

A ideia de temas geradores, inspirada em Paulo Freire (1991), é um recurso de análise interpretativa que facilita o entendimento das categorias da pesquisa, ao mesmo tempo em que é em elemento facilitador da condução das entrevistas, viabilizando maior aproximação entre entrevistadores e entrevistados. Durante as entrevistas, os temas são apresentados aos entrevistados para que possam refletir livremente, produzindo narrativas dos seus contextos, e possibilitando aos pesquisadores uma compreensão da realidade com poucas intervenções.

As subseções a seguir explicitam os contornos da investigação conforme o núcleo temático definido para análise, justificando as razões de suas escolhas.

\subsection{Política Educacional}

Compreendida como uma das manifestações das políticas públicas relativas ao "que o governo faz ou deixa de fazer" (SOUZA, 2006), a política educacional no Brasil sofre a influência de diversos grupos de interesse e processos decisórios que se traduzem de formas distintas na prática, distanciando-se, muitas vezes, do atendimento das reais necessidades da sociedade. Tal fato decorre da ausência de diálogo e de aproximação entre os grupos que definem as políticas públicas de educação e aqueles que as implementam no âmbito dos sistemas e das escolas. Nos últimos anos, os atores de implementação das políticas educacionais no país, tem sido, em larga medida, os 
do setor empresarial, o que, de acordo com Freitas (2018), intitula-se como um movimento de "reforma empresarial da educação". Dessa forma, observa-se que a influência desses setores perpassa o processo de formação, o currículo e a organização das redes de ensino, concebendo uma compreensão de educação própria que atenda aos anseios do mercado.

As responsabilidades na oferta da educação pública no Brasil, divididas entre a União, os estados, os municípios e o Distrito Federal, pressupõem articulação e cooperação entre os entes federados visando assegurar a redução das desigualdades de aprendizagem e uma educação de qualidade para todos. No entanto, essa proposição é de natureza complexa, gerando contornos diversos à produção e ao exercício prático da política educacional nas escolas.

$\mathrm{Na}$ ausência de um Sistema Nacional de Educação (SNE), a função normativa da União de condução das propostas políticas no campo educativo, assume um perfil centralizador, conduzindo e, por vezes, reduzindo a autonomia dos outros entes federados na proposição de políticas afinadas às suas especificidades.

A pesquisa buscou observar a presença de políticas federais, estaduais e municipais nas escolas, com destaque para ações do governo federal devido à sua abrangência no universo dos estabelecimentos de ensino. Assim, procurou-se investigar aspectos relacionados ao Sistema de Avaliação da Educação Básica (Saeb) e Índice de Desenvolvimento da Educação Básica (Ideb), ao Programa Nacional do Livro Didático (PNLD), ao Programa Nacional de Alimentação Escolar (PNAE), ao Programa Dinheiro Direto na Escola (PPDE) e ações relativas ao transporte escolar.

\section{2 Cidadania Global}

A educação é um “direito social” firmado pela Constituição Federal (CF) de 1988 (CF, Art. $\left.6^{0}\right)$. A formação para a cidadania é tema importante no campo dos valores e fins da educação. A Constituição é clara a esse respeito ao definir que "A educação, direito de todos e dever do Estado e da família, será promovida e incentivada com a colaboração da sociedade, visando ao pleno desenvolvimento da pessoa, seu preparo para o exercício da cidadania e sua qualificação para o trabalho (CF, 1988, Art. 205. Grifo dos autores).

Educação como direito social garante "a participação na riqueza coletiva” (CARVALHO, 2012, p. 10). Dessa forma, a educação possibilita a vida social e o exercício dos direitos políticos e civis, em resumo, o exercício da cidadania. Essa percepção do direito social da educação assumida pela $\mathrm{CF} / 1988$, registra um resgate histórico em defesa da democracia. Para falar de cidadania é preciso considerar para além da dimensão legal dos direitos sociais, como a educação e as condições objetivas de seu efetivo exercício. Não é suficiente que os direitos estejam presentes e garantidos 
nas leis, sem que haja uma mobilização estrutural mais ampla, capaz de modificar as realidades e diminuir as desigualdades sociais.

A escola pública, em sua função social, apresenta-se como espaço de potencialidade à formação cidadã de crianças, jovens e adultos. No entanto, estudos que fundamentam a discussão acerca da crise da escola pública elucidam que a formação para a cidadania acaba sendo minimizada frente ao atendimento das demandas das avaliações externas, a busca por melhoria dos indicadores de aprendizagem, bem como a constante precarização de suas estruturas e ofertas (FERREIRA; OLIVEIRA, 2009). Em um cenário de aceleração do processo de globalização mundial, ao mesmo tempo em que se vive uma revolução técnico-científica-informacional, uma parcela da população sofre com a privação e negação de direitos individuais e sociais básicos para a sobrevivência. Nesse contexto, novas demandas surgem em relação a uma formação para a cidadania global. Transitar em "territórios" virtuais requer alfabetização digital e científica, habilidades não demandadas às gerações forjadas sob a era industrial. A cidadania global, nesse sentido implica dominar saberes em constante processo de transformação, daí a relevância de "aprender a aprender" e dominar códigos linguísticos que viabilizem o acesso a esses saberes.

Colocando-se nesse campo de aprendizagens múltiplas e requerimentos de uma educação para a cidadania global, a Unesco se insere nesse debate posicionando-se sobre o tema e pautando essa discussão no cenário das agências multilaterais e dos países onde atua (UNESCO, s.d.).

Segundo a Unesco, para promover formação cidadã, a escola deve incluir, na organização do seu trabalho pedagógico junto às crianças e aos jovens, noções básicas da convivência humana, como o respeito ao outro e a compreensão de que os direitos estão inseridos em um processo que o individual e o coletivo se encontram em permanente interseção e diálogo, fortalecendo o protagonismo juvenil na luta pela justiça social, pelo respeito às diversidades e a sustentabilidade ambiental. Se a escola é um dos espaços onde crianças e jovens se formam para o exercício da cidadania, que relação existe entre os conceitos cidadania e a cidadania global na prática escolar? Estaria a escola pública brasileira cumprindo sua função social de formação cidadã e encaminhando-se para a formação do cidadão global? Pode parecer questões de simples resposta, mas, na prática, não é.

Segundo Santos (2002, p. 21),

aquilo que habitualmente designamos por globalização são, de facto, conjuntos diferenciados de relações sociais; diferentes conjuntos de relações sociais dão origem a diferentes fenómenos de globalização. Nestes termos, não existe estritamente uma entidade única chamada globalização; existem, em vez disso, globalizações; em rigor, este termo só deveria ser usado no plural. 
Considerando, portanto, esses processos ocorridos no mundo nas últimas décadas (SANTOS, 2002; TEODORO, 2011; OLSENN; CODD; O’NEILL, 2004), qualificar e ampliar este debate de modo a conceber formas de educação que considerem uma cidadania global é tema de crescente relevância para o campo da educação. Em um mundo onde as fronteiras dos Estadosnações tendem a ser mais e mais afetadas pela circulação do capital em tempo real, aumenta a relevância de melhor conhecer como este tema chega às escolas e as visões que nela circulam (ou não) acerca de tal temática.

\section{3 Diversidade territorial}

Sendo o Brasil um país de dimensões continentais, a diversidade territorial é tema que se impõe. Tendo por organização geopolítica o sistema federativo, o país tem sua população distribuída entre 27 estados e 5.570 municípios. A legislação brasileira define que a educação deve orientar-se pelo "regime de colaboração" (CF, 1988, Art. 11 e LDB, 1996, Art. 8), sendo esta responsabilidade compartilhada pela União, os estados, o Distrito Federal e os municípios. Considerando tal configuração, debruçar-se sobre a diversidade territorial das unidades federadas revelou-se um desafio central da pesquisa.

Tão importante quanto compreender as políticas que chegam às escolas no território nacional, é buscar um olhar mais detido sobre o ambiente geográfico onde as escolas estão situadas. Em que medida elas possuem uma estrutura física compatível com o território em que se localizam? Se não no passado, pelo menos no presente, diante das permanentes ameaças à sustentabilidade dos biomas brasileiros, a escola é uma instituição social em sintonia com tais questões?

Tendo apresentado os fundamentos e temas centrais da pesquisa, seguem-se elementos da metodologia adotada, de modo a esclarecer os procedimentos adotados no percurso da investigação.

\section{Metodologia da pesquisa}

A pesquisa utilizou o modelo misto de pesquisa que permite integrar procedimentos quantitativos e qualitativos dentro e ao longo dos estágios da investigação (JOHNSON; CHRISTENSEN, 2003). Distintas técnicas de coleta e de análise de dados foram empregadas para dar conta dos objetivos explicitados ou deles decorrentes. O planejamento da pesquisa foi organizado em fases, sendo o método quantitativo utilizado no primeiro momento, vindo a dar pistas para realização da pesquisa qualitativa, inclusive na elaboração dos instrumentos aplicados em campo. Quanto à análise qualitativa, foram adotadas estratégias metodológicas pertinentes ao 
estudo de casos múltiplos (YIN, 2005), uma vez que cada escola visitada se constituiu em um caso particular. Para analisar as entrevistas dos sujeitos da pesquisa, recorreu-se à análise de conteúdo temático-categorial (BARDIN, 2006; MAYRING, 2000).

O Quadro 1 apresenta a relação das 23 escolas, identificando-as por bioma, estado e município, assim como sua tipificação.

Quadro 1 - Relação das escolas por bioma, estado, município e tipo

\begin{tabular}{|c|c|c|c|c|c|}
\hline $\mathbf{N}$ & Bioma & Estado & Município & $\begin{array}{l}\text { Tipificação } \\
\text { da escola }\end{array}$ & Escola \\
\hline 1 & Amazônia & PA & Abaetetuba & Ribeirinha & EMEIF Sorriso de Maria \\
\hline 2 & Amazônia & PA & Tomé Açu & Quilombola & EMEIFQ Florência Inglis de Paiva \\
\hline 3 & Caatinga & $\mathrm{CE}$ & Fortaleza & Urbana & EEFM Dra. Aldaci Barbosa \\
\hline 4 & Caatinga & $\mathrm{CE}$ & Tauá & Rural & EEIF Pref Pedro P de Castro Castelo \\
\hline 5 & Caatinga & $\mathrm{RN}$ & Mossoró & Campo & EE Gilberto Rola \\
\hline 6 & Cerrado & $\mathrm{DF}$ & Brasília & Rural & Escola Classe Boa Vista \\
\hline 7 & Cerrado & DF & Brasília/Brazlandia & Rural & CED Irmã Regina \\
\hline 8 & Cerrado & DF & Brasília & Urbana & Centro de Ensino Médio Setor Oeste \\
\hline 9 & Cerrado & $\mathrm{DF}$ & Brasília & Urbana & $\begin{array}{l}\text { Centro de Ensino Fundamental } 104 \\
\text { Norte }\end{array}$ \\
\hline 10 & Mata Atlântica & RJ & Resende & Urbana & EM Prof Carlinhos \\
\hline 11 & Mata Atlântica & RJ & Resende & Urbana & EM Francisco Quirino Diniz \\
\hline 12 & Mata Atlântica & SP & São Paulo & Urbana & $\begin{array}{l}\text { EM Profa. Aurea Ribeiro Xavier } \\
\text { Lopes }\end{array}$ \\
\hline 13 & Mata Atlântica & SP & São Paulo & Urbana & EM Neuza Avelino da Silva Melo \\
\hline 14 & Mata Atlântica & $\mathrm{BA}$ & Maragogipe & Quilombola & EM Getúlio Vargas \\
\hline 15 & Mata Atlântica & $\mathrm{BA}$ & Cachoeira & Quilombola & EM Santiago do Iguape \\
\hline 16 & Mata Atlântica & ES & Aracruz & Indígena & EMI Três Palmeiras (Guarani) \\
\hline 17 & Mata Atlântica & ES & Aracruz & Indígena & EMI Caeiras Velha (Tupiniquim) \\
\hline 18 & Pampa & RS & Viamão & Indígena & $\begin{array}{l}\text { Escola Estadual Indígena Karaí } \\
\text { Arandu }\end{array}$ \\
\hline 19 & Pampa & RS & Tapes & Urbana & EMEF José Divino Barbosa Pereira \\
\hline
\end{tabular}




\begin{tabular}{|l|l|l|l|l|l|}
\hline $\mathbf{N}$ & Bioma & Estado & Município & $\begin{array}{l}\text { Tipificação } \\
\text { da escola }\end{array}$ & Escola \\
\hline 20 & Pantanal & MS & Aquidauana & Urbana & EM Erso Gomes \\
\hline 21 & Pantanal & MS & Aquidauana & Indígena & EM Indígena Ipegue \\
\hline 22 & Pantanal & MS & Aquidauana & Pantaneira & EM Pantaneira \\
\hline 23 & Pantanal & MS & Aquidauana & Indigena & EM Indígena Marcolino Lili \\
\hline
\end{tabular}

Fonte: Elaboração dos autores, 2021.

O mapa a seguir apresenta a localização das escolas nos respectivos biomas.

Mapa 1 - Localização das escolas por bioma

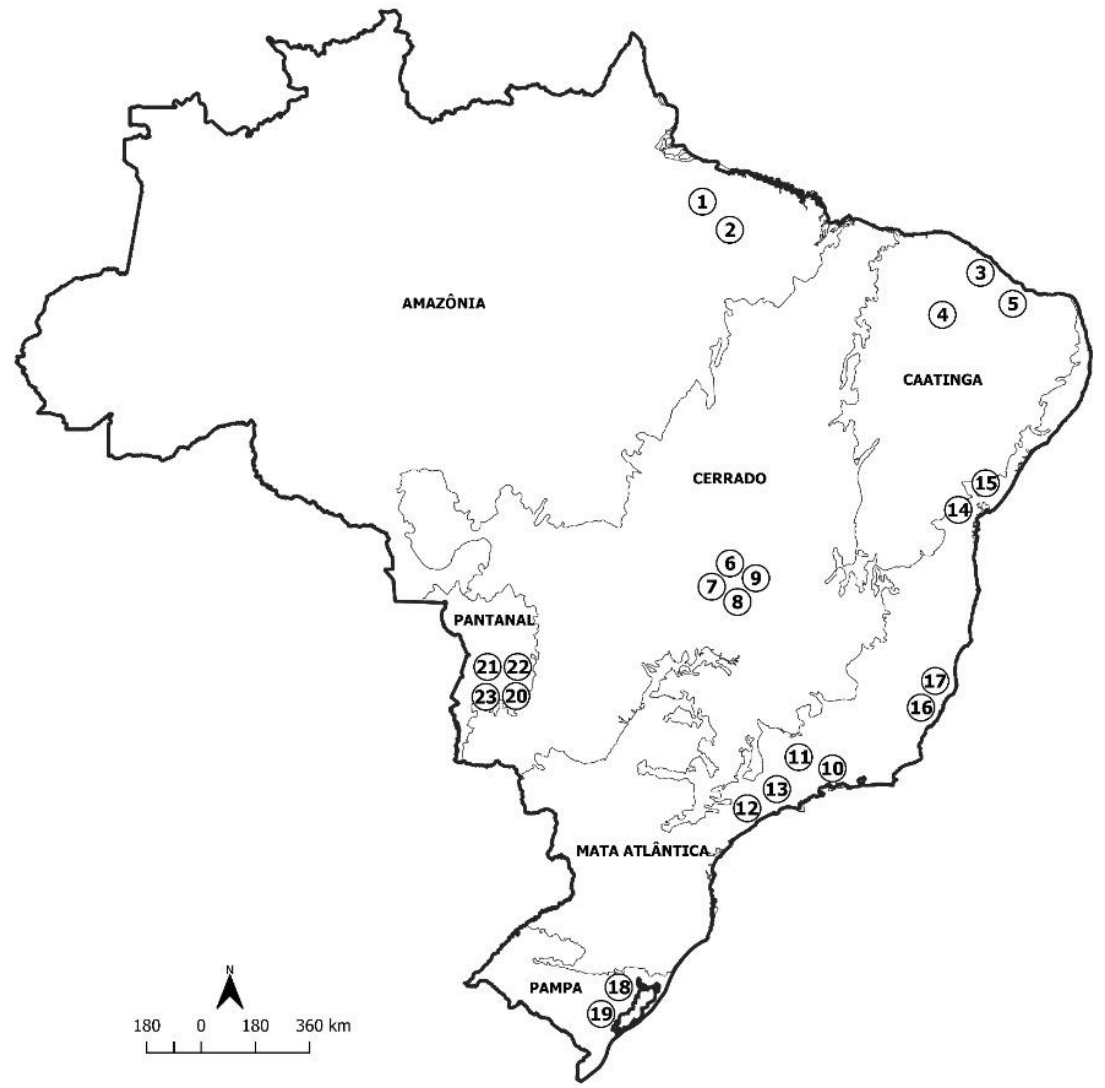

Fonte: Elaborado por W. Galvão, 2021

O estudo foi realizado em um total de 14 municípios localizados em nove estados da federação e no Distrito Federal, compreendendo nove escolas urbanas, cinco escolas indígenas, três escolas quilombolas, três escolas rurais, uma escola do campo, uma pantaneira e uma ribeirinha, representando, portanto, configurações territoriais diversas com peculiaridades próprias 
identificáveis por meio de características das populações, da localização geográfica e de condições econômicas e sociais.

A pesquisa de campo foi desenvolvida em diferentes etapas, contando com 20 participantes, entre professores pesquisadores, doutorandos, bolsistas de iniciação científica e uma consultora. Participaram da pesquisa cerca de 240 sujeitos, sendo a maior parte em 25 grupos focais de professores, alunos e familiares. Os diretores escolares participaram por meio de entrevista semiestruturada, em algumas situações contando também com a presença de coordenadores pedagógicos. Os dados quantitativos e qualitativos foram organizados em formato eletrônico, passíveis de análise pelos participantes da pesquisa.

\section{Primeiras aproximações sobre as escolas visitadas}

A pesquisa de campo foi desenvolvida na perspectiva de obter um olhar sistêmico sobre as 23 escolas localizadas nos seis biomas. Algumas observações merecem destaque a partir do que se viu, lembrando que, pelo caráter imbricado dos temas geradores da pesquisa, nem sempre é possível analisá-los em separado.

\subsection{Escolas em pleno funcionamento}

Uma primeira e importante observação a fazer sobre as escolas visitadas diz respeito à constatação de que o exercício cotidiano do processo de ensino-aprendizagem mostrou-se presente em todas as unidades, com raras exceções. Estas, no caso, foram motivadas pela ausência de aulas em virtude de processos formativos de professores, a exemplo de um local onde apenas as lideranças estavam presentes para receber a equipe de pesquisa (escola indígena - Bioma Mata Atlântica).

Por óbvio que pareça, é deste trabalho, ao mesmo tempo, simples e complexo que depende o exercício da função social da escola, onde, além do "pleno desenvolvimento da pessoa, da preparação para o exercício da cidadania” e da "qualificação para o trabalho" (CF, 1988, Art. 205), as tarefas de ensinar e aprender propiciam a socialização e aquisição da cultura historicamente acumulada pela humanidade.

\subsection{Presença de programas federais}

A pesquisa permitiu constatar que, em geral, os programas nacionais financiados pelo Ministério da Educação (MEC), tais como o PNLD, o PNAE, o PDDE e outros chegam às escolas, mas nem sempre em tempo hábil para suas necessidades cotidianas. Apesar das dificuldades e dos 
obstáculos à implementação das referidas iniciativas, porém, estas fazem parte de seu cotidiano, impactam em sua sobrevivência e repercutem sobre sua qualidade. Aqui é possível identificar elementos da governança educacional multiescalar (DALE, 2010), mediante a participação de atores não estatais no provimento de serviços.

O PNLD é uma iniciativa federal de grande porte que beneficia todas as escolas públicas brasileiras. Grandes editoras nacionais são forças de mercado atuantes nesse empreendimento. Nas escolas visitadas, de uma maneira geral, as referências ao programa foram positivas, embora tenha sido percebido pouco uso dos livros do programa em expressivo número de escolas. Situação diversa ocorreu em uma escola sem biblioteca em suas instalações, onde se notou extremo cuidado com os livros, percebendo-se a centralidade de seu uso no cotidiano escolar (escola ribeirinha Bioma Amazônia). Em uma das escolas do município de São Paulo (escola urbana - Bioma Mata Atlântica), foi identificado um belo espaço de leitura para além da biblioteca com estantes de livros nos corredores para livre manuseio pelas crianças. O cultivo de uma cultura de leitura, contudo, não foi igualmente observado em todas as escolas, percebendo-se, inclusive, alguns casos de dificuldade de lidar com os livros remanescentes do PNLD, seja por falta de criatividade, seja por questões de espaço físico.

O PNAE, também presente em todas as escolas públicas brasileiras, mostrou sua presença em visitas que ocorreram em diferentes horários de funcionamento e revelaram vários momentos de alimentação nas escolas visitadas. Foi possível, assim, perceber seus impactos no cotidiano escolar, notando-se sua centralidade na vida dos estudantes. Não foram observados comportamentos de rejeição à merenda, consumida com gosto pelas crianças, e, com frequência, também por professores. Na maioria das escolas há responsáveis pelo preparo da alimentação em suas próprias instalações, à exceção do município de São Paulo, onde esta atividade é terceirizada, revelando uma outra face das forças de mercado na governança. Notou-se perfeita integração entre os responsáveis pela alimentação, professores e outros profissionais da escola e estudantes.

Os relatos de diretores indicaram que, para a maioria das escolas, os recursos do PDDE representam importante instrumento de solução de pequenos problemas de manutenção cotidiana. Lembrando que a maioria de unidades federadas possui programas próprios de financiamento direto às escolas, é oportuno lembrar que, em apenas uma escola, houve referência ao mau uso desses recursos pelo diretor, afastado de suas funções por processo administrativo, vindo a ser substituído, o que teve por consequência suspensão de transferências diretas à escola até a solução do problema. 


\subsection{Dificuldades na gestão do transporte escolar}

O transporte escolar é um capítulo à parte em grande número das escolas visitadas, em particular, naquelas situadas fora do perímetro urbano. São muito expressivos os segmentos de alunos que dependem do transporte escolar para sua locomoção entre o local de moradia e a escola. Esse pode ser um grande problema para a gestão escolar. Com maior ou menor grau de dificuldade, as crianças chegam às escolas diariamente. Na maioria das escolas visitadas, esse transporte é feito por veículos como ônibus, nem sempre em condições satisfatórias de manutenção, a exemplo de escolas do Bioma Pantanal, algumas muito distantes da sede do município, situação que obriga crianças a viajarem várias horas por dia para chegar à escola.

Nas escolas visitadas no Bioma Amazônia, o transporte das crianças às escolas é feito por barcos. Observou-se extremo zelo por parte dos adultos envolvidos no processo. Em uma situação específica, os pesquisadores tiveram oportunidade de acompanhar as crianças se deslocando em conjunto até o local onde estavam os barcos. Foi comovente verificar o cuidado de umas com as outras, atravessando uma passagem molhada pela chuva torrencial do dia anterior. Uma escola do bioma caatinga tem seu ano escolar prejudicado em decorrência da estação chuvosa e do fechamento dos acessos por veículos motorizados, às vezes, por semanas.

Para os gestores escolares, lidar com as dificuldades de transporte é tarefa desafiante, sujeita a toda sorte de dificuldades. Os provedores desse serviço nem sempre dialogam com as escolas numa percepção equivocada de que sua relação é com a instituição contratante, ou seja, as secretarias de educação. Consertos de veículos não são feitos em tempo hábil, e os processos de contratação de veículos, por vezes, interrompem as rotinas de transporte. É verdade que o Ministério da Educação possui um programa específico de transporte escolar - Caminho da Escola -, mas, segundo os entrevistados, representa apenas "um grão de areia" no atendimento às necessidades de deslocamento. As falas dos entrevistados indicaram que o financiamento dessa atividade representa um pesado ônus para estados, municípios e escolas. As questões do território são determinantes dos problemas estruturais que afetam o transporte escolar.

\subsection{Diferenciação na implementação das políticas educacionais}

Outra constatação relativa à implementação de políticas é que, em virtude de circunstâncias diversas, os modos de implementação diferem em função das peculiaridades dos territórios, da mediação exercida pelos órgãos municipais ou estaduais do sistema educacional e da identidade de cada escola. O esforço das secretarias de educação para fazer essas iniciativas chegarem ao chão da escola também não é o mesmo nos contextos examinados. Nesse caso, cabe assinalar a influência 
diferenciada da capacidade financeira dos distintos entes federados na implementação de políticas. Não é possível comparar uma escola do campo em um município do interior do Nordeste (escola do campo - Mossoró/RN) com uma escola de uma grande metrópole como São Paulo.

Embora o estudo não tenha tido o objetivo de identificar como as políticas transitam no âmbito dos órgãos do sistema, foi possível perceber diferenças que dizem respeito a um maior ou menor distanciamento entre secretarias e escolas. A despeito de eventuais problemas nesta articulação, na maioria dos estabelecimentos visitados, os diretores identificaram como positivas as relações entre os órgãos do sistema e as escolas.

\subsection{Heterogeneidade dos impactos da avaliação externa}

Ainda em relação às políticas educacionais implementadas no âmbito escolar, questão relevante da pesquisa articulou-se à forma como as escolas lidam com o desafio das políticas de avaliação de larga escala em seu cotidiano. Nesse sentido, verificou-se que, embora estas cheguem à maioria das escolas, nem sempre representam parâmetros para suas ações cotidianas. Aqui é possível perceber que o modo como "as escolas fazem as políticas" difere em função de sua cultura organizacional. Algumas conhecem seus próprios indicadores educacionais e orientam muitas de suas ações para a melhoria dos resultados dos estudantes.

Outras, em menor número, contudo, parecem estar em um mundo onde a avaliação externa ainda não faz parte de sua cultura cotidiana. É, com certeza, o caso das escolas que, por alguma razão, não participam das aplicações de prova do Saeb, como as escolas diferenciadas (quilombolas, indígenas e ribeirinha) e, também, de outras que, surpreendentemente, têm os exames presentes em sua rotina, mas passam ao largo de seus efeitos sobre a escola. Em outras, ainda, há forte presença de uma cultura de avaliação e responsabilização, caso daquelas situadas nos estados do Ceará, Espírito Santo e São Paulo. Percebe-se, assim, o entrelaçamento entre a forma como "as escolas fazem as políticas" e os contextos de sua "atuação".

\subsection{Cidadania global versus cidadania local}

Para aprofundar o tema da Educação para a Cidadania Global (ECG), palavras-chave na agenda das políticas do século XXI, o estudo analisou documentos de política educacional brasileira. Constatou-se que questões relativas à cidadania e educação para a cidadania estão presentes em documentos estratégicos de política educacional brasileira - Constituição (1998), Lei de Diretrizes e Bases da Educação Nacional (1996) e Base Nacional Comum Curricular de 2017. 
Em termos de uma agenda de governança, verificou-se a presença de questões relacionadas à ECG ao nível supranacional (UNESCO, s. d.). Nas escalas nacional (federal), subnacional (estadual) e local (municipal), não foi possível identificar evidências da presença de iniciativas e/ou programas relacionados ao tema. Durante o trabalho de campo, foi possível constatar que os temas da cidadania e da cidadania global, em geral, suscitaram pouca receptividade junto aos entrevistados. Percebeu-se que as escolas públicas observadas, com esforço, têm buscado cumprir suas atribuições relativas ao ensino e à aprendizagem. Notou-se uma percepção incipiente de uma formação ampliada de cidadania como tarefa da escola. Considerando o protagonismo das avaliações externas, as preocupações das escolas tendem a se concentrar e se organizar em torno de demandas mais urgentes e com foco na responsabilização de seus atores.

A ideia de uma Educação para a Cidadania (Global) parece passar ao largo das preocupações dos entrevistados, tendência confirmada na maioria dos diálogos com diretores, professores, estudantes e famílias. Observou-se, inclusive, certo desconforto entre os entrevistados quando indagados sobre o tema. Práticas de formação para a cidadania, contudo, se mostraram presentes em algumas escolas da amostra.

Exemplos de registros de práticas de cidadania nesse sentido foram a escola ribeirinha do bioma Amazônia, onde todos convivem em harmonia; uma das escolas quilombolas do Bioma Mata Atlântica, em que a cidadania faz parte do currículo; uma das escolas indígenas do Bioma Mata Atlântica, onde foi identificada uma comunidade escolar com plena consciência de seus direitos; a escola rural do Bioma Mata Atlântica, espaço de convivência e participação ativa das famílias na gestão, e a escola do Bioma Caatinga, que, embora não se referisse à cidadania global, desenvolvia um conjunto de atividades locais associadas ao conceito.

\subsection{Diversificação da infraestrutura escolar no território}

Outro aspecto importante aprofundado na pesquisa diz respeito ao espaço físico e às condições de infraestrutura escolar permeadas pela diversidade territorial. Como em relação às subseções anteriores, foi possível notar expressivas diferenças entre os estabelecimentos de ensino. A visita a escolas de diferentes características, no que se refere a um "padrão mínimo de qualidade", permitiu observar significativa heterogeneidade. Em algumas, foi possível identificar conformidade com o que se espera da estrutura física de uma escola, independentemente de seu tamanho. Uma escola rural do bioma Caatinga tinha sido recentemente inaugurada num prédio cuja infraestrutura possuía espaços pedagógicos modernos e dispunha de recursos didáticos bastante satisfatórios. 
Outras não chamaram atenção especial sobre suas instalações. Embora representassem exceções, foram identificadas instalações com evidentes problemas de infraestrutura e de manutenção.

Em relação a essa matéria, vale observar que, na pesquisa, o espaço físico não se mostrou determinante da qualidade do trabalho observado, embora sejam evidentes as condições limitantes por ele impostas. Se a "alma” das escolas, por assim dizer, pode ser associada à sua estrutura, há algo em seu interior que transcende a dimensão do espaço físico, cuja constituição se coloca no ethos criado pelas equipes escolares.

Uma das expressivas diferenças na infraestrutura das escolas diz respeito ao seu terreno e ao seu período de construção. De uma maneira geral, as escolas visitadas mostraram-se como espaços sem vegetação e com nenhum ou escasso diálogo com a natureza em seu entorno.

\subsection{Escassa presença de iniciativas de sustentabilidade ambiental}

A opção por incluir, na amostra, escolas localizadas no território dos biomas brasileiros decorreu do interesse por identificar se as preocupações com a sustentabilidade, e as questões socioambientais têm sido priorizadas nas políticas educacionais que chegam à escola. Observou-se que estas, em geral, pouco consideram as especificidades territoriais, seja na zona urbana ou rural. Salvo algumas exceções, a preocupação com tais temas não se mostrou uma característica marcante das escolas visitadas, embora depoimentos tenham apresentado informações sobre o conceito ser trabalhado no currículo da disciplina de Geografia, em sintonia com outros aspectos relativos ao meio ambiente.

É oportuno mencionar algumas exceções no que se refere à relação da escola com o meio ambiente. Foi o caso da escola ribeirinha, localizada no Bioma Amazônia, que funciona em perfeita integração com o lugar onde está situada. Situação semelhante foi encontrada em relação à escola Pantaneira, no Bioma Pantanal, situada em uma fazenda distante da sede do município e em plena harmonia com seu entorno. Igualmente foi possível notar preocupações ambientais na escola urbana de Visconde de Mauá, em Resende/RJ. Em uma das escolas da cidade de São Paulo, havia um espaço livre que começava a ser explorado em aulas práticas de conteúdos de Ciências. A relação com a natureza se mostrou presente em duas das escolas (Aracruz/ES e Viamão/RS). Na escola da Caatinga, foram identificados projetos de conservação da mata nativa, aproveitamento de água da chuva e coleta seletiva de lixo junto à comunidade na qual está localizada.

O que se viu, sem dúvida, é pouco face à urgência de uma nova visão sobre a Terra, a natureza e a interação humana com seu ambiente. Seria de se esperar uma harmonia entre as escolas e a paisagem natural do bioma que as acolhem. Não foi isso que se viu como regra. Tais 
constatações remetem às dificuldades relativas à implementação das propostas curriculares brasileiras, uma vez que, desde a proposição dos Parâmetros Curriculares Nacionais (BRASIL, MEC, 1997), o tema transversal meio ambiente se faz presente nos materiais didáticos e nas ações de formação continuada. A Base Nacional Comum Curricular (BNCC), por sua vez, retoma e atualiza essa reflexão (BRASIL, MEC, s. d.). Incorporá-la às práticas curriculares no cotidiano escolar é desafio que se impõe.

\section{Considerações finais}

O desafio de conhecer escolas em um país de dimensões continentais não é empreendimento simples. Como assinala Bacelar (2008), na epígrafe deste artigo, as três heranças legadas pelo processo de conquista do território brasileiro deixaram marcas profundas na constituição do Estado-nação, que perduram até os dias atuais. Ao selecionar os temas geradores, a pesquisa pode projetar luzes sobre essas três heranças.

Quanto à "vastidão do espaço geográfico", foi possível verificar in loco a complexidade de um país marcado por uma paisagem diversificada e com peculiaridades distintas. Considerando o modelo federativo do país, em que cabe à União a concepção e coordenação da política educacional, trata-se de um grande desafio viabilizar uma cadeia de transmissão fluida e célere para chegar a 26 Estados e o Distrito Federal, aos 5.570 municípios e às 139.176 escolas públicas distribuídas no território brasileiro (BRASIL, INEP, 2019, p. 40). Se as políticas chegam às escolas, a diversidade territorial é fator a ser mais bem equacionado no trânsito entre as instâncias da governança educacional multiescalar.

O caminho percorrido pela Expedição mostrou a presença da "forte assimetria regional" de que fala Bacelar (s.d.). De maneira geral, observou-se que as escolas localizadas nas unidades federadas com maiores recursos, de fato, possuem condições de infraestrutura significativamente mais satisfatórias que as demais, caso marcante das escolas visitadas no município de São Paulo. Localizadas em bairros periféricos, apresentaram boas condições de funcionamento, com materiais e alimentação escolar diferenciados. Muito distinta foi a situação das escolas de territórios pobres, onde a simplicidade das instalações se revelou constante e marcante.

Quanto às "escandalosas desigualdades sociais", é oportuno observar que, o cotidiano das escolas públicas brasileiras, em maior ou menor grau, é atravessado por tais características, como já demostraram estudos sobre a matéria (ALVES; SOARES; XAVIER, 2016; ERNICA; RODRIGUES, 2020). Não foi diferente em relação às escolas visitadas, e foi possível notar que as marcas das desigualdades não se distribuem de forma homogênea. Algumas unidades contam com 
presença significativa de crianças de classe média, enquanto outras são frequentadas por alunos que vivem em situação de pobreza e em contextos de grande vulnerabilidade social.

A análise dos temas geradores à luz dos fundamentos teóricos permitiu perceber a relevância da adoção dessas lentes interpretativas para compreender o objeto em foco. Nesse sentido foi possível constatar a fecundidade da teoria da governança educacional multiescalar de Dale (2010) para explicar o modo como as políticas educacionais percorrem as instâncias nacionais e subnacionais no processo de sua implementação.

As contribuições de Ball, Maguire e Braun (2016) permitiram compreender como "as escolas fazem as políticas" e, ainda, que estas são marcadas pelas condições de sua "cultura organizacional", como mostra Torres (2005), respondendo às políticas com base na interação entre estrutura (formal) e ação (informal), assim como em fatores exógenos e endógenos. Não por acaso, a interação entre as escolas e seu entorno, seja o meio físico, seja o humano, é tão diferenciada. Cada escola é fruto de uma história que lhe confere uma identidade, que define como as políticas são por ela acolhidas ou secundarizadas. Seu espaço de autonomia, por sua vez, é determinante de seus modos de ser. Finalmente, a relação da escola com a cidadania global pareceu frágil e pouco efetiva na maioria dos estabelecimentos, apesar de preocupações expressas sobre o significado da cidadania numa sociedade democrática.

Os primeiros achados da pesquisa apontam para uma diversidade de instituições comprometidas com sua função social de acolher e formar as novas gerações transmitindo o legado dos saberes produzidos para as gerações futuras. Suas ações e suas iniciativas, não raro, são contingenciadas por carências estruturais, inerentes às próprias políticas educacionais as quais, por vezes, elegem prioridades desconectadas com as necessidades das escolas. Ao mesmo tempo, a frágil presença de práticas curriculares voltadas para a sustentabilidade socioambiental evidencia que há muito por caminhar para viabilizar uma aproximação mais sistêmica entre as escolas e os ecossistemas onde se situam. Se é no chão onde as pessoas convivem cotidianamente que se dá a vida em sociedade, a escola pode e deve tornar-se um espaço de convivência mais harmônica com o território. Políticas que focalizem tais desafios são necessárias e inadiáveis.

\section{Referências}

ALVES, M. T. G..; SOARES, J. F.; XAVIER, F. P. Desigualdades educacionais no ensino fundamental de 2005 a 2013: hiato entre grupos sociais. Revista Brasileira de Sociologia, Vol. 04, $\mathrm{n}^{\circ}$. 07. Jan - Jun, 2016. Disponível em: http://dx.doi.org/10.20336/rbs.150.

BACELAR, T. Globalização e Território. 2008. Disponível em: https://diplomatique.org.br/globalizacao-e-territorio/. Acesso em: 02 set. 2021. 
BALL, S. J.; MAGUIRE, M.; BRAUN, A. Como as escolas faz̧em as políticas: atuação em escolas secundárias. Trad.: Janete Bridon. Ponta Grossa: Editora UEPG, 2016.

BARDIN, L. Análise de conteúdo. 4. ed. Lisboa: Edições 70, 2006.

BRASIL. Presidência da República. Casa Civil. Subchefia para Assuntos Jurídicos. Constituição da República Federativa do Brasil de 1988. Disponível em:

http://www.planalto.gov.br/ccivil_03/constituicao/ constituicao.htm. Acesso em: mai. de 2021.

BRASIL. Presidência da República. Casa Civil. Subchefia para Assuntos Jurídicos. Lei n 9.394, de 20 de dezembro de 1996. Estabelece as diretrizes e bases da educação nacional. Disponível em: http://www.planalto.gov.br/ ccivil_03/leis/19394.htm. Acesso em: mai. de2021.

BRASIL. MEC. Base Nacional Comum Curricular: educação é a base. s.d. Disponível em: http://basenacionalcomum.mec.gov.br/images/BNCC_EI_EF_110518_versaofinal_site.pdf Acesso em: ago. de 2021.

BRASIL MEC. Parâmetros curriculares nacionais: introdução aos parâmetros curriculares nacionais / Secretaria de Educação Fundamental. - Brasília : MEC/SEF, 1997. Disponível em: http://portal.mec.gov.br/seb/arquivos/pdf/livro01.pdf Acesso em: 07 ago. 2021.

BRASIL. MEC. INEP. Sinopse Estatística da Educação Básica 2019. Brasília: Instituto Nacional de Estudos e Pesquisas Educacionais Anísio Teixeira. Disponível em:

http://https//download.inep.gov.br/informacoes_estatisticas/sinopses_estatisticas/sinopses_ed ucacao_basica/sinopse_estatistica_educacao_basica_2019.zip. Acesso em: 03 set. 2021.

CARVALHO, José Murilo de. Cidadania no Brasil. O longo Caminho. $15^{\mathrm{a}}$ ed. Rio de Janeiro: Civilização Brasileira, 2012.

DALE, Roger. A sociologia da educação e o estado após a globalização. Educ. Soc., Campinas, v.31, n.113, p.1099-1120, out-dez 2010. Disponível em: https://doi.org/10.1590/S0101$73302010000400003>$.

ERNICA, M.; RODRIGUES, E. C. Desigualdades educacionais em metrópoles: território, nível socioeconômico, raça e gênero. Educ. Soc., Campinas, v. 41, e228514, 2020. Disponível em: https://doi.org/10.1590/ES.228514.

FREIRE, P. Educação como prática de liberdade. 20. ed. Rio de Janeiro: Paz e Terra, 1991.

FREITAS, Luiz Carlos de. A reforma empresarial da educação: nova direita, velhas ideias. São Paulo: Expressão Popular, 2018.

FERREIRA, E. \& OLIVEIRA, D. A. Crise da Escola e Politicas Educativas. Belo Horizonte: Autêntica, 2009.

JOHNSON, B.; CHRISTENSEN, L. B. Educational research: quantitative, qualitative, and mixed approaches. 2 ed. Boston: Allyn \& Bacon. 2003.

MAYRING, P. Qualitative content analysis. Forum: Qualitative Social Research [On-line Journal], v. 1, n. 2. 2000. 
MEC. Parâmetros Curriculares Nacionais Ensino Fundamental - Meio Ambiente. Brasília: DF. 1997. Disponível em: http://portal.mec.gov.br/seb/arquivos/pdf/ meioambiente.pdf. Acesso em: 5 ago. 2021.

MOREIRA, A. M. de A.; AIRES, C. J. A avaliação do Pacto Nacional pelo Fortalecimento do Ensino Médio na percep̧ãa de gestores escolares do Distrito Federal - Brasil. Lisboa: EDUCA/ Secção Portuguesa da AFIRSE, 2015.

OLSSEN, M.; CODD, J.; OÑEILL, A-M. Education policy, citizenship and democracy. SAGE: Los Angeles, 2004.

SANTOS, B. de S. Towards a new legal common sense. London: Butterworth, 2002.

SETUBAL, M. A. Educação e sustentabilidade princípios e valores para a formação de educadores. São Paulo, Petrópolis, 2015.

SOUZA, C. Políticas Públicas: uma revisão da literatura. Sociologias, Porto Alegre, ano 8, $\mathrm{n}^{\circ} 16$, jul/dez 2006, p. 20-45. Disponível em: https://www.scielo.br/j/soc/a/6YsWyBWZSdF gfSqDVQhc4jm/?format=pdf\&lang=pt. Acesso em: mai. de 2020.

TEODORO, A. A educaşão em tempos de globalização neoliberal os novos modos de regulação das políticas educacionais. Brasilia: Liber Livro, 2011, p 23-45.

TORRES, A. E. S. Generative Themes in Qualitative Research Methodology, 2014.

TORRES, L. L. Cultura organizacional no contexto escolar: o regresso à escola como desafio na reconstrução de um modelo teórico. Ensaio: aval. pol. Públ. Educ. vol. 13 n. 49. Rio de Janeiro, Oct./Dec. 2005. Disponível em: https://doi.org/10.1590/S0104-40362005000400003.

UNESCO. Educação para a cidadania global: a abordagem da UNESCO. S.d. Disponível em: http://www.unesco.org/new/fileadmin/MULTIMEDIA/FIELD/Brasilia/ pdf/brz_ed_global_citizenchip_brochure_pt_2015.pdf Acesso em: 04 ago. 2021.

VIDAL, E. M.; VIEIRA, S. L. (orgs.). Educação e território: contribuição ao debate na região do Maciço de Baturité, Ceará. Volume 1. Fortaleza, Liber Livro, 2014.

WERLE, F. O. C.; , KOETZ, C. M.; MARTINS, T. de F. K.. Escola pública e a utilização de indicadores educacionais. Educação, v. 38, p. 99, 2015. Disponível em: https://doi.org/10.15448/1981-2582.2015.1.11686.

WERLE, F. O. C.; AUDINO, J. F. Desafios na gestão escolar. RBPAE, Revista Brasileira de Política e Administração da Educação, v. 31, p. 125-144, 2015. Disponível em: https://doi.org/10.21573/vol31n12015.58921.

YIN, R. K. Estudo de caso: planejamento e métodos. 3. Ed. Porto Alegre: Bookman, 2005. 